(2) Open Access Full Text Article

REVIEW

\title{
Current status of vandetanib (ZD6474) in the treatment of non-small cell lung cancer
}

This article was published in the following Dove Press journal:

Biologics: Targets \& Therapy

24 August 2010

Number of times this article has been viewed

\author{
Jaclyn Flanigan \\ Hari Deshpande \\ Scott Gettinger \\ Yale Cancer Center/Yale University \\ School of Medicine New Haven, \\ CT, USA
}

\begin{abstract}
Vandetanib (ZD6474) is an oral small molecule inhibitor of multiple intracellular receptor kinases, including the vascular endothelial growth factor receptor (VEGFR) -2 and epidermal growth factor receptor (EGFR). Both VEGFR and EGFR pathways have emerged as instrumental in the growth and metastasis of multiple malignancies, including non-small cell lung cancer (NSCLC). Indeed, inhibitors of each pathway have been approved by the US Food and Drug Administration for use in advanced NSCLC. As there is considerable cross talk between these pathways, dual inhibition with such agents has become an attractive strategy, with encouraging Phase II clinical trial data to date. The convenience of one oral agent targeting both pathways is clear, and clinical trials have established the maximum tolerated daily dose of vandetanib, with data from randomized Phase III trials emerging. This report will review completed and ongoing NSCLC clinical trials evaluating vandetanib, and speculate on the future of this agent in NSCLC.
\end{abstract}

Keywords: Zactima, ZD6474, non-small cell lung cancer, vandetanib

\section{Introduction}

Lung cancer continues to be the leading cause of cancer related mortality worldwide, accounting for over one million deaths annually. ${ }^{1}$ The majority of patients present with metastatic disease, with a median survival of six months. ${ }^{2}$ Approximately $85 \%$ of lung cancers are classified as non-small cell lung cancer (NSCLC), which can be further subdivided in adenocarcinoma, squamous cell carcinoma and large cell carcinoma histology. Chemotherapy remains the cornerstone of treatment in advanced NSCLC; however, a plateau of effectiveness with such therapy has been reached. Molecularly targeted agents have further improved outcome over the last decade, and several additional targeted agents are being developed.

To date, three targeted agents have been approved by the US Food and Drug Administration (FDA) in advanced NSCLC. The first to receive FDA approval was gefitinib, a small molecule inhibitor of the epidermal growth factor receptor (EGFR) tyrosine kinase, a transmembrane receptor whose activation leads to intracellular signaling involved in cancer cell proliferation and survival. Gefitinib was later restricted to use only in those who were previously benefiting, as a Phase III trial comparing gefitinib to best supportive care did not ultimately find a survival advantage. ${ }^{3}$ The second drug to be granted approval was erlotinib, another small molecule inhibitor of the EGFR tyrosine kinase, which is currently indicated as second or third line therapy in patients with advanced NSCLC. The last FDA-approved agent is bevacizumab, a humanized
Correspondence: Scott N Gettinger

333 Cedar Street, FMP I27,

New Haven, CT 06530, USA

Tel +l 2037857564

Fax + I 2037853788

Email scott.gettinger@yale.edu 
monoclonal antibody to the vascular endothelial growth factor (VEGF), a key mediator of angiogenesis required for growth and metastasis of cancer. A trial conducted by the Eastern Cooperative Oncology Group (ECOG) found that the addition of bevacizumab to first line chemotherapy with carboplatin and paclitaxel led to improved response and survival, with a landmark median survival of one year. ${ }^{4}$ Cetuximab is another promising monoclonal antibody which targets the extracellular ligand binding domain of EGFR, and a recent Phase III study found a modest improvement in survival when this agent was combined with cisplatin and vinorelbine in patients with chemonaive advanced NSCLC. ${ }^{5}$ The US FDA is currently considering approval of this drug.

Clearly, the EGFR and VEGF pathways have been clinically validated as important targets in the treatment of NSCLC. Preclinical studies further suggest that combined inhibition of both pathways may lead to synergistic effects on cancer cell growth, survival and metastases..$^{6-8}$ The rationale for dual inhibition comes from our increased understanding of the redundancy of these pathways and their interconnectedness.

\section{Vascular endothelial growth factor receptor (VEGFR) Pathway}

Three transmembrane receptors mediate the angiogenic and lymphogenic effects of VEGF; VEGFR-1 (Flt-1), -2 (KDR), and -3 (Flt-4). ${ }^{9}$ Of these, VEGFR-2 is believed to play the primary role in endothelial cell proliferation, migration, survival and induction of vascular permeability characteristic of neo-vascularization required for tumor growth and metastasis. ${ }^{10,11}$ VEGFR-2 is activated by binding of VEGF elaborated by tumor cells, which leads to receptor dimerization and intracellular signaling initiated by the VEGFR tyrosine kinase. ${ }^{11,12}$ This ultimately results in the production of tumor vasculature that is highly permeable, dilated and tortuous, with increased tumor interstitial pressure that may impede delivery of cytotoxic agents. ${ }^{13}$ The resultant increasingly hypoxic microenvironment in turn upregulates expression of VEGF contributing to further neo-vascularization.

\section{EGFR Pathway}

Like the VEGFR, the EGFR is activated by ligand (ie, EGF, TGF- $\alpha$ ) binding leading to receptor dimerization and autophosphorylation of its intracellular tyrosine kinase domain. This kinase in turn phosphorylates other proteins, initiating a cascade of signaling events responsible for cell proliferation, cell survival, metastasis and angiogenesis. ${ }^{14}$ EGFR is overexpressed in several solid tumors, including NSCLC. ${ }^{15}$ Activating mutations in the EGFR gene have additionally been identified that lead to constitutive activity of the intracellular tyrosine kinase and predict for high response rates to the small molecule EGFR inhibitors, erlotinib and gefitinib. ${ }^{16-19}$ Although only approximately $10 \%-15 \%$ of NSCLCs harbor EGFR mutations, it is estimated that up to $50 \%$ of lifelong nonsmokers with NSCLC have EGFR mutant tumors. ${ }^{20}$ The reliance of these mutant tumors on the EGFR pathway has led to the term oncogene addiction.

\section{Crosstalk between VEGFR and EGFR Pathways}

Both in vitro and in vivo data have established that activation of EGFR by its ligands can lead to increased VEGFR expression and neovascularization in cancer models. ${ }^{21,22}$ Indeed, both small molecule inhibitors and antibodies to EGFR (and downstream signaling mediators) have resulted in decreased VEGF expression and cell death in cancer cell lines and animal models. ${ }^{23-25}$ VEGF over expression may also mediate resistance to EGFR antagonists, with preclinical data supporting efforts to overcome acquired resistance with the addition of a VEGF inhibitor, and delaying emergence of resistance with upfront dual inhibition. ${ }^{26}$ Combining bevacizumab and erlotinib in the clinic is a particularly appealing strategy, considering good tolerance of each agent alone, with lack of overlapping toxicities. This regimen has been well tolerated in a Phase II NSCLC clinical trial that showed promising activity, and the final results of two Phase III trials are awaited. ${ }^{27-29}$

\section{Vandetanib (ZD6474, Zactima ${ }^{\text {TM}}$; AstraZeneca) (N-(4-bromo-2- fluorophenyl)-6-methoxy-7- [( I-methylpiperidin-4-yl)methoxy] quinazolin-4-amine)}

Vandetanib is an oral anilinquinazoline that competes with ATP binding in the catalytic domain of several tyrosine kinases. ${ }^{30}$ Recombinant enzyme assays haves shown it to be a potent inhibitor of VEGFR-2 (50\% inhibitory concentration $\left[\mathrm{IC}_{50}\right]$ of $40 \mathrm{nM}$ ), with additional activity against VEGFR-3 $\left(\mathrm{IC}_{50} 110 \mathrm{nM}\right)$, EGFR ( $\left.\mathrm{IC}_{50} 500 \mathrm{nM}\right)$ and the rearranged during transfection (RET; $\mathrm{IC}_{50} 130 \mathrm{nM}$ ) kinase. Further studies on human umbilical vein endothelial cells (HUVEC) have found vandetanib to potently inhibit proliferation of VEGFR stimulated cells ( $\mathrm{IC}_{50} 60 \mathrm{nM}$ ) with higher doses necessary for EGFR stimulated HUVEC proliferation $\left(\mathrm{IC}_{50} 170 \mathrm{nM}\right)$. Additional in vitro and in vivo studies have also demonstrated that vandetanib inhibits cell growth of several human cancer cell 
lines that have functional EGFR but are devoid of VEGFR-2, and further potentiates the anti-proliferative effects of docetaxel and paclitaxel..$^{21,31}$ Xenograft models have in turn shown dose dependent inhibition of tumor growth with vandetanib, including NSCLC tumors resistant to gefitinib, and reduction in tumor microvessel density and inhibition of new blood vessel formation. ${ }^{30,32-34}$ Together, these and other preclinical studies suggest the effect of vandetanib on tumor growth and survival is mediated by both the EGFR and VEGR pathways, and support further clinical evaluation.

\section{Phase I studies}

Two Phase I dose escalation studies evaluating daily vandetanib alone in advanced solid tumors have been completed. The first was conducted in the United States and Australia, enrolling 77 patients, with colon cancer being the most common tumor type.$^{35}$ Dose limiting toxicities included diarrhea, hypertension and rash. The recommended dose to evaluate in further studies was $300 \mathrm{mg}$ daily. This dose was tolerated well, with the most common toxicities being rash and diarrhea. Asymptomatic QTc prolongation was also observed in 7 patients. Pharmacokinetic studies showed vandetanib to be extensively distributed, with a half life of approximately 120 hours and a minimum of 28 days continuous oral dosing required to achieve steady-state plasma concentrations. The second Phase I study was conducted in Japan, and enrolled 18 patients. ${ }^{36}$ Again, $300 \mathrm{mg}$ daily was determined to be the recommended dose with similar toxicity profile and pharmacokinetic findings. Of note, four of nine patients with advanced refractory NSCLC achieved a partial response per Response Evaluation Criteria in Solid Tumors (RECIST) criteria at doses of 200 or $300 \mathrm{mg}$ daily.

A third Phase I trial further evaluated vandetanib in combination with pemetrexed, a newer anti-folate approved for use in advanced nonsquamous NSCLC. ${ }^{37}$ Only patients with advanced NSCLC who failed first line chemotherapy were eligible. Two dose levels of vandetanib were evaluated, $100 \mathrm{mg}$ and $300 \mathrm{mg}$ daily, given with full doses of pemetrexed every three weeks. Both doses were well tolerated, without obvious pharmacokinetic interactions. Of the 21 patients enrolled, one achieved a partial response by RECIST criteria (from the vandetanib $100 \mathrm{mg}$ cohort), and an additional 13 patients had stabilization of disease.

\section{Phase II studies}

Based on encouraging activity in Phase I studies with good tolerability of vandetanib up to $300 \mathrm{mg}$ daily, four randomized Phase II trials evaluating vandetanib alone and in combination with chemotherapy have been conducted in advanced NSCLC (Table 1). ${ }^{38-41}$ These trials confirmed the good tolerability of vandetanib seen in Phase I studies, with modest activity supporting Phase III evaluations. The most common side effects experienced were rash, diarrhea, hypertension, and asymptomatic prolonged QTc interval. In the two studies where vandetanib was combined with chemotherapy, there were no pharmacokinetic interactions. Interestingly, the study evaluating two dose levels of vandetanib with standard docetaxel dosing suggested that a lower dose of vandetanib may be more beneficial when combined with chemotherapy. One hypothesis offered to explain this has been that with greater inhibition of EGFR achieved with higher doses of vandetanib, cancer cell proliferation is decreased with G1 cell cycle arrest compromising effectiveness of cell cycle phase-dependent activity of chemotherapy. ${ }^{42}$ Four Phase III trials evaluating the addition of a small molecule EGFR inhibitor (erlotinib or gefitinib) to standard first line chemotherapy support this, with no benefit appreciated. ${ }^{43-46}$

Correlative studies from the randomized Phase II studies included serum markers (ie, several cytokines and angiogenic factors including VEGF) and tumor tissue analysis for EGFR and KRAS mutational status, and EGFR gene copy number by FISH. ${ }^{38,41,47,48}$ Limited samples preclude any conclusions; however, there was a suggestion that circulating VEGF levels may be a potential biomarker, with lower values being more predictive of benefit. Additional biomarker studies are clearly needed, and such analyses from Phase III studies are awaited.

\section{Phase III studies}

Three Phase III clinical trials evaluating vandetanib were presented at the American Society of Clinical Oncology (ASCO) annual meeting in 2009 and are awaiting formal publication. Two of the studies investigated vandetanib in combination with standard second-line chemotherapy, and the third compared vandetanib to erlotinib.

\section{ZEST}

Based on the Phase II study by Natale et $\mathrm{al}^{39}$ showing promising data for vandetanib versus gefitinib as monotherapy in previously treated NSCLC (Table 1), the ZEST (ZACTIMA Efficacy Study versus Tarceva) trial was designed with the primary objective to show superiority in progression-free survival (PFS) for vandetanib versus erlotinib. ${ }^{49} \mathrm{~A}$ total of 1,240 patients with advanced lung cancer who had received previous therapy (all histologies permitted) were randomized in a 2:1 fashion to either vandetanib $300 \mathrm{mg} /$ day $(\mathrm{n}=623)$ or erlotinib $150 \mathrm{mg} /$ day $(\mathrm{n}=617)$. 
Table I Randomized NSCLC clinical trials evaluating vandetanib

\begin{tabular}{|c|c|c|c|c|}
\hline $\begin{array}{l}\text { Study } \\
\text { \# Pts \# prior chemo }\end{array}$ & Design & RR (\%) & PFS* & $\begin{array}{l}\text { OS } \\
(\mathrm{m})\end{array}$ \\
\hline \multicolumn{5}{|c|}{ Randomized Phase II Trials } \\
\hline Kiura $2008^{38}$ & All arms & 13 & TTP & - \\
\hline \multirow[t]{3}{*}{$53 / 1-2$} & I. V $100 \mathrm{mg}$ & 17.6 & 8.3 weeks & \\
\hline & 2. V $200 \mathrm{mg}$ & 5.6 & 12.3 weeks & \\
\hline & 3. $\vee 300 \mathrm{mg}$ & 16.7 & 12.3 weeks & \\
\hline Natale $2009^{39}$ & I. V $300 \mathrm{mg}$ & 8 & 8.1 weeks & 6.1 \\
\hline \multirow[t]{2}{*}{$168 / 1-2$} & 2. Gefitinib 250 mg daily; & 1 & II.3 weeks & 7.4 \\
\hline & crossover allowed & & HR $.69, P=0.013$ & NS \\
\hline Heymach $2007^{40}$ & I. Docetaxel + V 100 mg & 26 & 18.7 weeks $^{\wedge}$ & 13.1 \\
\hline \multirow[t]{3}{*}{$|27 /|$} & 2. Docetaxel + V $300 \mathrm{mg}$ & 18 & 17 weeks & 7.9 \\
\hline & 3. Docetaxel & 12 & 12 weeks $^{\wedge}$ & 13.4 \\
\hline & & & ^HR $0.64, P=0.037$ & \\
\hline Heymach $2008^{41}$ & I. Carboplatin/Paclitaxel + V $300 \mathrm{mg}$ & 32 & 24 weeks (I). & 10.2 \\
\hline \multirow[t]{3}{*}{ |8I/chemonaive } & 2. Carboplatin/Paclitaxel & 25 & 23 weeks (2) & 12.6 \\
\hline & 3. $\vee 300 \mathrm{mg}$ & & HR 0.76; $P=0.098$ & NS \\
\hline & & & [V alone arm closed] & \\
\hline \multicolumn{5}{|l|}{ Phase III Trials } \\
\hline Natale $2009^{49}$ & I. V $300 \mathrm{mg}$ & 12 & II.3 weeks & 6.9 \\
\hline ZEST & 2. Erlotinib & 12 & 8.9 weeks & 7.8 \\
\hline$|240 /|-2$ & & & HR 0.98; $P=0.721$ & NS \\
\hline De Boer $2009^{50}$ & I. Pemetrexed + V $100 \mathrm{mg}$ & 19 & 17.6 weeks & 10.5 \\
\hline ZEAL & 2. Pemetrexed & 8 & 11.9 weeks & 9.2 \\
\hline $534 / 1$ & & & HR $0.86 ; P=0.108$ & NS \\
\hline Herbst $2009^{51}$ & I. Docetaxel + V 100 mg & 17 & 4 months & 10.6 \\
\hline ZODIAC & 2. Docetaxel & 10 & 3.2 months & 10 \\
\hline 1391// & & & HR 0.79; $P<0.001$ & NS \\
\hline
\end{tabular}

Note: *PFS primary endpoint of all trials except Kiura et al study ${ }^{38}$ where RR was primary endpoint.

Abbreviations: RR, response rate; PFS, progression-free survival; OS, overall survival; $m$, months; TTP, time to progression; V, vandetanib (given once daily in all studies); NS, not statistically significant.

After a median duration of follow up of 14 months, this study failed to show any difference in PFS for patients treated with vandetanib (hazard ratio [HR] 0.98; 95.22\% confidence interval [CI]: 0.87-1.10; $P=0.721)$. Secondary endpoints including overall survival, objective response rate, and time to deterioration of symptoms were similar in both groups. There was a higher incidence of adverse events in the vandetanib group, including diarrhea, hypertension, and rash.

\section{ZEAL}

The ZEAL (ZACTIMA Efficacy with Alimta in Lung cancer) trial evaluated the addition of vandetanib to pemetrexed. ${ }^{50}$ The prior Phase I trial of this combination by De Boer et $\mathrm{al}^{37}$ demonstrated the safety and tolerability of vandetanib when given with pemetrexed. Vandetanib doses of $100 \mathrm{mg}$ /day were better tolerated than doses of $300 \mathrm{mg} /$ day. This observation and the concern about theoretical antagonism with chemotherapy from greater EGFR inhibition achieved with the $300 \mathrm{mg}$ dose led De Boer and colleagues to choose the
$100 \mathrm{mg}$ dose in the ZEAL study. Patients were randomized to vandetanib $100 \mathrm{mg} /$ day plus pemetrexed $500 \mathrm{mg} / \mathrm{m}^{2}$ every three weeks $(n=256)$ versus placebo plus pemetrexed $(n=278)$, with the primary endpoint of PFS. Secondary endpoints included overall survival, objective response rate, time to deterioration of symptoms, and safety. Patients received up to six cycles of chemotherapy. All patients had advanced NSCLC previously treated with first-line therapy and all histologies were included. After a median follow up duration of nine months, this study showed a trend for improved PFS (HR, 0.86; 97.58\% CI: 0.69-1.06, $P=0.108$ ) and OS (HR, 0.86 ; 97.54\% CI: $0.65-1.13 ; P=0.219$ ); however, these results were not statistically significant. As demonstrated in other studies, the adverse events with vandetanib were most commonly rash (Grade 3+: $38 \%$ in vandetanib arm vs $26 \%$ in placebo arm), diarrhea (26\% vs $18 \%$ ), and hypertension ( $12 \%$ vs $3 \%$ ). Interestingly, typical side effects of pemetrexed, such as anemia, fatigue, nausea, vomiting, were reduced in the arm receiving vandetanib. 


\section{ZODIAC}

The Phase III ZODIAC (ZACTIMA in cOmbination with Docetaxel In non-smAll cell lung Cancer) trial randomized over one thousand patients with advanced NSCLC who had received first line chemotherapy to two groups: vandetanib 100 $\mathrm{mg} /$ day plus docetaxel $75 \mathrm{mg} / \mathrm{m}^{2}$ every three weeks $(\mathrm{n}=694)$ or to placebo plus docetaxel $(n=697) .{ }^{51}$ Patients were given up to 6 cycles of chemotherapy. This study had a median duration of follow up of 12.8 months. This study met its primary endpoint by demonstrating a statistically significant improvement in PFS for the arm treated with vandetanib plus docetaxel (HR, 0.79; 97.58\% CI: $0.70-0.90 ; P<0.001)$. Median PFS was 8.9 months in those receiving vandetanib and 4 months in those in the chemotherapy only arm. Difference in overall survival; however, was not statistically significant in those receiving vandetanib (HR, 0.91; 97.52\% CI: $0.78-1.07 ; P=0.196$ ). Not surprisingly, the adverse event profile was similar to that previously observed with vandetanib in NSCLC. Patients in the vandetanib arm experienced more diarrhea, rash, and neutropenia. The incidence of protocol-defined QTc prolongation was $<2 \%$ in patients receiving vandetanib.

\section{Conclusions}

The future of vandetanib in NSCLC is uncertain. In late October 2009, Astra Zeneca announced that it was withdrawing regulatory submissions for use of vandetanib $100 \mathrm{mg}$ in combination with docetaxel in patients with advanced NSCLC after initial application to the US FDA and the European Medicines Agency in June 2009. This was based on only modest PFS with no overall survival advantage with the addition of vandetanib to docetaxel

Table 2 Ongoing/pending trials of vandetanib in NSCLC

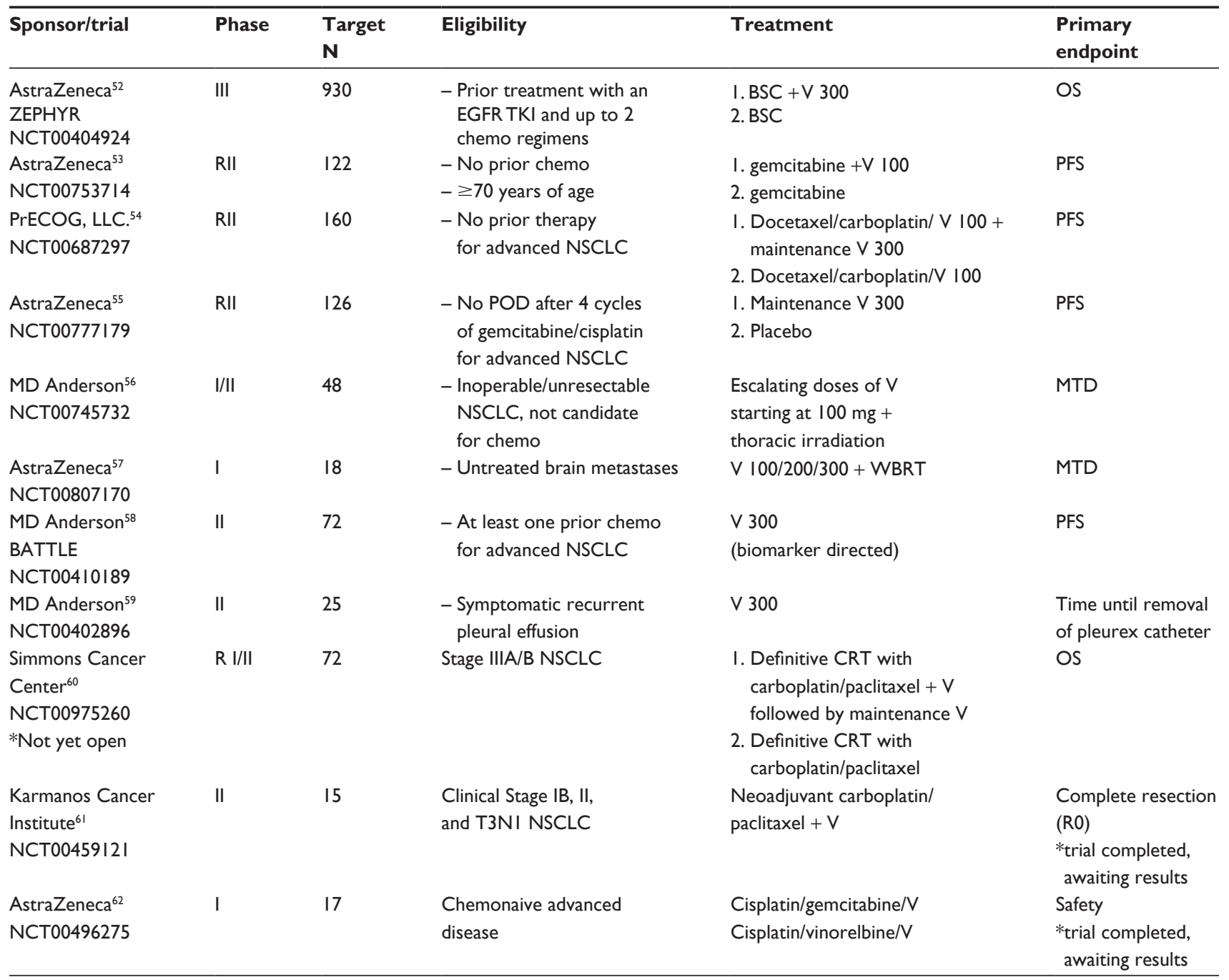

Abbreviations: $\mathrm{N}$, number of patients; EGFR, epidermal growth factor receptor; TKI, tyrosine kinase inhibitor; BSC, best supportive care; $\mathrm{V}$, vandetanib given once daily; R, randomized; POD, progression of disease; PFS, progression-free survival; MTD, maximum tolerated dose; WBRT, whole brain irradiation; CRT, chemoradiation; OS, overall survival. 
in the ZODIAC trial. With negative results of the ZEAL and ZEST trial presented at the annual ASCO conference last year, further evaluation of vandetanib as monotherapy or with pemetrexed in unselected patients with NSCLC is unlikely. There are still several ongoing clinical trials evaluating vandetanib in various settings (see Table 2), and the results of these will help determine if an indication will be reached in NSCLC. Of particular importance will be the identification of clinical and molecular predictors of benefit from vandetanib, and correlative biomarkers from randomized trials are awaited. Without such predictors, further development of Zactima in NSCLC is unlikely.

\section{Disclosure}

No funding was provided for the preparation of the paper. None of the authors have any conflicts of interest with regard to submission of this manuscript.

\section{References}

1. Kamangar F, Dores GM, Anderson WF. Patterns of cancer incidence, mortality, and prevalence across five continents: defining priorities to reduce cancer disparities in different geographic regions of the world. J Clin Oncol. 2006;24:2137-2150.

2. Goldstraw P, Crowley J, Chansky K, et al. The IASLC Lung Cancer Staging Project: Proposals for the Revision of the TNM Stage Groupings in the Forthcoming (Seventh) Edition of the TNM Classification of Malignant Tumours. J Thorac Oncol. 2007;2:706-714.

3. Thatcher N, Chang A, Parikh P, et al. Gefitinib plus best supportive care in previously treated patients with refractory advanced nonsmall-cell lung cancer: results from a randomised, placebo-controlled, multicentre study (Iressa Survival Evaluation in Lung Cancer). Lancet. 2005;366:1527-1537.

4. Sandler A, Gray R, Perry MC, et al. Paclitaxel-carboplatin alone or with bevacizumab for non-small-cell lung cancer. $N$ Eng J Med. 2006;355: 2542-2550.

5. Pirker R, Pereira JR, Szczesna A, et al. Cetuximab plus chemotherapy in patients with advanced non-small-cell lung cancer (FLEX): an openlabel randomised phase III trial. Lancet. 2009;373:1525-1531.

6. Ciardiello F, Bianco R, Damiano V, et al. Antiangiogenic and antitumor activity of anti-epidermal growth factor receptor C225 monoclonal antibody in combination with vascular endothelial growth factor antisense oligonucleotide in human GEO colon cancer cells. Clin Cancer Res. 2000;6:3739-3747.

7. Guy SP, Ashton S, Hughes G, et al. Gefitinib (Iressa, ZD1839) enhances the activity of the novel vascular-targeting agent ZD6126 in human colorectal cancer and non-small cell lung cancer (NSCLC) xenograft models. Clin Cancer Res. 2003;9:6142s (abstract B13).

8. Tonra JR, Deevi DS, Corcoran E, et al. Synergistic antitumor effects of combined epidermal growth factor receptor and vascular endothelial growth factor receptor-2 targeted therapy. Clin Cancer Res. 2006;12: 2197-2207.

9. Robinson DR, Wu YM, Lin SF. The protein tyrosine kinase family of the human genome. Oncogene. 2000;19:5548-5557.

10. Gille H, Kowalski J, Li B, et al. Analysis of biological effects and signaling properties of Flt-1 (VEGFR-1) and KDR (VEGFR-2). A reassessment using novel receptor-specific vascular endothelial growth factor mutants. J Biol Chem. 2001;276:3222-3230.

11. Ferrara N, Gerber HP, LeCouter J. The biology of VEGF and its receptors. Nat Med. 2003;9:669-676.

12. Munoz-Chapuli R, Quesada AR, Angel Medina M. Angiogenesis and signal transduction in endothelial cells. Cell Mol Life Sci. 2004;61: 2224-2243.
13. Jain RK. Normalization of tumor vasculature: An emerging concept in antiangiogenic therapy. Science. 2005;307:58-62.

14. Olayioye MA, Neve RM, Lane HA, Hynes NE. The ErbB signaling network: receptor heterodimerization in development and cancer. Embo J. 2000;19:3159-3167.

15. Isobe T, Herbst RS, Onn A. Current management of advanced non-small cell lung cancer: targeted therapy. Semin Oncol. 2005;32:315-328.

16. Lynch TJ, Bell DW, Sordella R, et al. Activating mutations in the epidermal growth factor receptor underlying responsiveness of non-small-cell lung cancer to gefitinib. N Engl J Med. 2004;350:2129-2139.

17. Paez JG, Janne PA, Lee JC, et al. EGFR mutations in lung cancer: correlation with clinical response to gefitinib therapy. Science. 2004; 304:1497-1500.

18. Paz-Ares L, Sanchez JM, García-Velasco A, et al. A prospective phase II trial of erlotinib in advanced non-small cell lung cancer (NSCLC) patients (p) with mutations in the tyrosine kinase (TK) domain of the epidermal growth factor receptor (EGFR). J Clin Oncol. 2006 ASCO Annual Meeting Proceedings Part I. 2006;24:7020.

19. MokTS, Wu Y-L, Thongprasert S, et al. Gefitinib or carboplatin-paclitaxel in pulmonary adenocarcinoma. $N$ Engl J Med. 2009;361: 947-957.

20. Pham D, Kris MG, Riely GJ, et al. Use of cigarette-smoking history to estimate the likelihood of mutations in epidermal growth factor receptor gene exons 19 and 21 in lung adenocarcinomas. J Clin Oncol. 2006;24:1700.

21. Ciardiello F, Caputo R, Damiano V, et al. Antitumor effects of ZD6474, a small molecule vascular endothelial growth factor receptor tyrosine kinase inhibitor, with additional activity against epidermal growth factor receptor tyrosine kinase. Clin Cancer Res. 2003;9:1546-1556.

22. De Luca A, Carotenuto A, Rachiglio A, et al. The role of the EGFR signaling in tumor microenvironment. $J$ Cell Physiol. 2008;214:559-567.

23. Hirata A, Ogawa S, Kometani T, et al. ZD1839 (Iressa) induces antiangiogenic effects through inhibition of epidermal growth factor receptor tyrosine kinase. Cancer Res. 2002;62:2554-2560.

24. Petit AM, Rak J, Hung MC, et al. Neutralizing antibodies against epidermal growth factor and ErbB-2/neu receptor tyrosine kinases down-regulate vascular endothelial growth factor production by tumor cells in vitro and in vivo: Angiogenic implications for signal transduction therapy of solid tumors. Am J Pathol. 1997;151:1523-1530.

25. Bianco R, Garofalo S, Rosa R, et al. Inhibition of mTOR pathway by everolimus cooperates with EGFR inhibitors in human tumours sensitive and resistant to anti-EGFR drugs. Br J Cancer. 2008;98:923-930.

26. Viloria-Petit AM, Kerbel RS. Acquired resistance to EGFR inhibitors: Mechanisms and prevention strategies. Int J Radiat Oncol Biol Phys. 2004;58:914-926.

27. Herbst RS, O'Neill VJ, Fehrenbacher L, et al. Phase II study of efficacy and safety of bevacizumab in combination with chemotherapy or erlotinib compared with chemotherapy alone for treatment of recurrent or refractory non small-cell lung cancer. J Clin Oncol. 2007; 25:4743-4750.

28. Hainsworth RH. A phase III, multicenter, placebo-controlled, double-blind, randomized clinical trial to evaluate the efficacy of bevacizumab (Avastin) in combination with erlotinib (Tarceva) compared with erlotinib alone for treatment of advanced non-small cell lung cancer after failure of standard first-line chemotherapy (BETA). Thoracic Oncol. 2008;3:S302.

29. Miller VA, O'Connor P, Soh C, Kabbinavar F. A randomized, double-blind, placebo-controlled, phase IIIb trial (ATLAS) comparing bevacizumab (B) therapy with or without erlotinib (E) after completion of chemotherapy with B for first-line treatment of locally advanced, recurrent, or metastatic non-small cell lung cancer (NSCLC). J Clin Onco l. 2009;27:18s (abstract LBA8002)

30. Wedge SR, Ogilvie DJ, Dukes M et al. ZD6474 inhibits vascular endothelial growth factor signaling, angiogenesis, and tumor growth following oral administration. Cancer Res. 2002;62:4645-4655.

31. Arao T, Fukumoto H, Takeda M, et al. Small in-frame deletion in the epidermal growth factor receptor as a target for ZD6474. Cancer Res. 2004;64:9101-9104.

32. Taguchi F, Koh Y, Koizumi F, et al. Anticancer effects of ZD6474, a VEGF receptor tyrosine kinase inhibitor, in gefitinib ("Iressa")-sensitive and resistant xenograft models. Cancer Sci. 2004;95:984-989. 
33. Ciardiello F, Bianco R, Caputo R, et al. Antitumor activity of ZD6474, a vascular endothelial growth factor receptor tyrosine kinase inhibitor, in human cancer cells with acquired resistance to antiepidermal growth factor receptor therapy. Clin Cancer Res. 2004;10:784-793.

34. Wu W, Onn A, Isobe T, et al. Targeted therapy of orthotopic human lung cancer by combined vascular endothelial growth factor and epidermal growth factor receptor signaling blockade. Mol Cancer Ther. 2007; 6:471-483.

35. Holden SN, Eckhardt SG, Basser R, et al. Clinical evaluation of ZD6474, an orally active inhibitor of VEGF and EGF receptor signaling, in patients with solid, malignant tumors. Ann Oncol. 2005;16: 1391-1397.

36. Tamura T, Minami H, Yamada Y, et al. A phase I dose-escalation study of ZD6474 in Japanese patients with solid, malignant tumors. J Thorac Oncol. 2006;1:1002-1009.

37. De Boer R, Humblet Y, Wolf J, et al. An open-label study of vandetanib with pemetrexed in patients with previously treated non-small-cell lung cancer. Ann Oncol. 2009;20:486-491.

38. Kiura K, Nakagawa K, Shinkai T, et al. A randomized, double-blind, phase IIa dose-finding study of vandetanib (ZD6474) in Japanese patients with non-small cell lung cancer. J Thorac Oncol. 2008;3:386-393.

39. Natale RB, Bodkin D, Govindan R, et al. Vandetanib versus gefitinib in patients with advanced non-small-cell lung cancer: Results from a two-part, double-blind, randomized phase II study. J Clin Oncol. 2009; 27:2523-2529.

40. Heymach JV, Johnson BE, Prager D, et al. Randomized placebo-controlled phase II study of vandetanib plus docetaxel in previously treated non small-cell lung cancer. J Clin Oncol. 2007;25:4270-4277.

41. Heymach JV, Paz-Ares L, De Braud F, et al. Randomized phase II study of vandetanib alone or with paclitaxel and carboplatin as first-line treatment for advanced non-small-cell lung cancer. J Clin Oncol. 2008; 26:5407-5415.

42. Davies AM, Ho C, Lara PN, et al. Pharmacodynamic separation of epidermal growth factor receptor tyrosine kinase inhibitors and chemotherapy in non-small-cell lung cancer. Clin Lung Cancer. 2006; 7:385-388.

43. Herbst RS, Prager D, Hermann R, et al. TRIBUTE: a phase III trial of erlotinib hydrochloride (OSI-774) combined with carboplatin and paclitaxel chemotherapy in advanced non-small-cell lung cancer. J Clin Oncol. 2005;23:5892-5899.

44. Gatzemeier U, Pluzanska A, Szczesna A, et al. Phase III study of erlotinib in combination with cisplatin and gemcitabine in advanced non-small-cell lung cancer: the Tarceva Lung Cancer Investigation Trial. J Clin Oncol. 2007;25:1545-1552.

45. Herbst RS, Giaccone G, Schiller JH, et al. Gefitinib in combination with paclitaxel and carboplatin in advanced non-small-cell lung cancer: a phase III trial-INTACT 2. J Clin Oncol. 2004; 22: $785-794$

46. Giaccone G, Herbst RS, Manegold C, et al. Gefitinib in combination with gemcitabine and cisplatin in advanced non-small-cell lung cancer: a phase III trial - INTACT 1. J Clin Oncol. 2004;22:777-784.

47. Hanrahan EO, Ryan AJ, Mann H, et al. Baseline vascular endothelial growth factor concentration as a potential predictive marker of benefit from vandetanib in non-small cell lung cancer. Clin Cancer Res. 2009; $15: 3600-3609$

48. Hanrahan EO, Lin HY, Kim ES, et al. Distinct patterns of change in plasma cytokine and angiogenic factors and markers of benefit for vandetanib and/or chemotherapy in non-small cell lung cancer patients. J Clin Oncol. 2010;28:193-201.

Biologics: Targets \& Therapy

\section{Publish your work in this journal}

Biologics: Targets \& Therapy is an international, peer-reviewed journal focusing on the patho-physiological rationale for and clinical application of Biologic agents in the management of autoimmune diseases, cancers or other pathologies where a molecular target can be identified This journal is indexed on PubMed Central, CAS, EMBase, Scopus
49. Natale RB, Thongprasert S, Greco FA, et al. Vandetanib versus erlotinib in patients with advanced non-small cell lung cancer (NSCLC) after failure of at least one prior cytotoxic chemotherapy: a randomized, double-blind phase III trial (ZEST). J Clin Oncol. 2009;27:abstract 8009.

50. De Boer R, Arrieta O, Gottfried M, et al. Vandetanib plus pemetrexed versus pemetrexed as second-line therapy in patients with advanced non-small cell lung cancer (NSCLC): a randomized, double-blind phase III trial (ZEAL). J Clin Oncol. 2009;27:409s:abstract 8010.

51. Herbst RS, Sun Y, Korfee S, et al. Vandetanib plus docetaxel versus docetaxel as second-line treatment for patients with advance non-small cell lung cancer (NSCLC): a randomized, double-blind phase III trial (ZODIAC). J Clin Oncol. 2009;27:807s:abstract CRA8003.

52. US National Institutes of Health. ZD6474 (ZACTIMATM) Phase III Study in EGFR Failures. Aug 10, 2010. Available from: http://clinicaltrials.gov/ct2/show/NCT00404924. Accessed Aug 11, 2010.

53. US National Institutes of Health. Zactima in Non Small Cell Lung Cancer (NSCLC) ELderly Patients In Combination With or Versus Gemcitabine (ZELIG). Jul 13, 2010. Available from: http://clinicaltrials. gov/ct2/show/NCT00753714. Accessed Aug 11, 2010.

54. US National Institutes of Health. Study of Vandetanib Combined With Chemotherapy to Treat Advanced Non-small Cell Lung Cancer. Dec 1, 2009. Available from: http://clinicaltrials.gov/ct2/show/NCT00687297. Accessed Mar 21, 2010.

55. US National Institutes of Health. Phase II of Zactima Maintenance for Locally Advanced or Metastatic NSCLC Following Platinum-doublet Chemotherapy. June 28, 2010. Available from: http://clinicaltrials.gov/ ct2/show/NCT00777179. Accessed Aug 11, 2010

56. US National Institutes of Health. Radiation Therapy (XRT)and ZD6474 in Non-Small Cell Lung Cancer (NSCLC). Apr 1, 2010. Available from: http://clinicaltrials.gov/ct2/show/NCT00745732. Accessed Aug 11, 2010.

57. US National Institutes of Health. Investigate the Maximum Tolerated Dose of Vandetanib and Concurrent Whole Brain Radiotherapy (WBRT) in Patients With Non-small Cell Lung Cancer (NSCLC) and Brain Metastases. Jan 25, 2010. Available from: http://clinicaltrials.gov/ct2/ show/NCT00807170. Accessed Mar 21, 2010.

58. US National Institutes of Health. BATTLE Program: ZD6474 in Previously Treated Subjects With NSCLC. Feb 26, 2010. Available from: http://clinicaltrials.gov/ct2/show/NCT00410189. Accessed Mar 21, 2010.

59. US National Institutes of Health. Malignant Pleural Effusion With ZD6474. Jan 6, 2010. Available from: http://clinicaltrials.gov/ct2/show/ NCT00402896. Accessed Mar 21, 2010.

60. US National Institutes of Health. Paclitaxel, Carboplatin, and High-Dose Radiation Therapy With or Without Vandetanib in Treating Patients With Stage IIIA or Stage IIIB Non-Small Cell Lung Cancer. Oct 7, 2009. Available from: http://clinicaltrials.gov/ct2/show/NCT00975260. Accessed Mar 21, 2010

61. US National Institutes of Health. Vandetanib, Carboplatin, and Paclitaxel in Treating Patients With Stage I, Stage II, or Stage III Non-Small Cell Lung Cancer That Can Be Removed by Surgery. Feb 6, 2009. Available from: http://clinicaltrials.gov/ct2/show/NCT00459121. Accessed Mar $21,2010$.

62. US National Institutes of Health. Phase I Combination With Vinorelbine or Gemcitabine Plus Cisplatin in Locally Advanced or Metastatic NSCLC. Apr 8, 2009. Available from: http://clinicaltrials.gov/ct2/show/ NCT00496275. Accessed Mar 21, 2010.

\section{Dovepress}

and the Elsevier Bibliographic databases. The manuscript management system is completely online and includes a very quick and fair peerreview system, which is all easy to use. Visit http://www.dovepress. $\mathrm{com} /$ testimonials.php to read real quotes from published authors. 